\title{
BMJ Open Effectiveness of continence promotion for older women via community organisations: a cluster randomised trial
}

\author{
Cara Tannenbaum, ${ }^{1}$ Rona Agnew ${ }^{2}$ Andrea Benedetti, ${ }^{3}$ Doneal Thomas, ${ }^{4}$ \\ Eleanor van den $\mathrm{Heuvel}^{5}$
}

To cite: Tannenbaum C, Agnew R, Benedetti A, et al. Effectiveness of continence promotion for older women via community organisations: a cluster randomised trial. BMJ Open 2013;3:e004135. doi:10.1136/bmjopen-2013004135

- Prepublication history for this paper is available online. To view these files please visit the journal online (http://dx.doi.org/10.1136/ bmjopen-2013-004135).

Received 27 September 2013 Revised 5 November 2013 Accepted 7 November 2013

CrossMark

For numbered affiliations see end of article.

Correspondence to Dr Cara Tannenbaum; cara. tannenbaum@umontreal.ca

\section{ABSTRACT}

Objectives: The primary objective of this cluster randomised controlled trial was to compare the effectiveness of the three experimental continence promotion interventions against a control intervention on urinary symptom improvement in older women with untreated incontinence recruited from community organisations. A second objective was to determine whether changes in incontinence-related knowledge and new uptake of risk-modifying behaviours explain these improvements.

Setting: 71 community organisations across the UK. Participants: 259 women aged 60 years and older with untreated incontinence entered the trial; $88 \%$ completed the 3-month follow-up.

Interventions: The three active interventions consisted of a single 60 min group workshop on (1) continence education (20 clusters, 64 women); (2) evidence-based self-management (17 clusters, 70 women); or (3) combined continence education and self-management (17 clusters, 61 women). The control intervention was a single 60 min educational group workshop on memory loss, polypharmacy and osteoporosis (17 clusters, 64 women).

Primary and secondary outcome measures: The primary outcome was self-reported improvement in incontinence 3 months postintervention at the level of the individual. The secondary outcome was change in the International Consultation on Incontinence Questionnaire (ICIQ) from baseline to 3-month followup. Changes in incontinence-related knowledge and behaviours were also assessed.

Results: The highest rate of urinary symptom improvement occurred in the combined intervention group (66\% vs $11 \%$ of the control group, prevalence difference $55 \%, 95 \% \mathrm{Cl} 43 \%$ to $67 \%$, intracluster correlation 0 ). $30 \%$ versus $6 \%$ of participants reported significant improvement respectively (prevalence difference $23 \%, 95 \% \mathrm{Cl} 10 \%$ to $36 \%$, intracluster correlation 0 ). The number-needed-to-treat was 2 to achieve any improvement in incontinence symptoms, and 5 to attain significant improvement. Compared to controls, participants in the combined intervention reported an adjusted mean 2.05 point $(95 \% \mathrm{Cl} 0.87$ to 3.24) greater improvement on the ICIQ from baseline to 3-month follow-up. Changes in knowledge and selfreported risk-reduction behaviours paralleled rates of improvement in all intervention arms.

\section{Strengths and limitations of this study}

- First study to provide level 1 evidence that continence promotion is an effective strategy for improving urinary symptoms among untreated community-dwelling older women.

- Participants were recruited via community organisations with representation across diverse socioeconomic strata.

- Rates of knowledge acquisition and behaviour change provide an explanatory mechanism for the observed improvements in incontinence in participants receiving the combined education plus self-management strategy.

- Only self-reported outcomes and crude dichotomous measures of behaviour change were collected so results must be interpreted with caution.

Conclusions: Continence education combined with evidence-based self-management improves symptoms of incontinence among untreated older women. Community organisations represent an untapped vector for delivering effective continence promotion interventions.

Trial registration: ClinicalTrials.gov ID number NCT01239836.

\section{INTRODUCTION}

Urinary incontinence is more frequent than breast cancer, heart disease or diabetes among older women, but remains a stigmatised and untreated condition despite its high prevalence. ${ }^{1-4}$ In the USA, Canada, the UK and other European countries, up to $40 \%$ of women aged 65 years and older experience involuntary urine leakage, but little more than $15-30 \%$ seek care. ${ }^{1-4}$ Even fewer physicians feel competent evaluating or treating incontinence. ${ }^{56}$ Urinary incontinence is associated with obesity, cardiovascular disease, diabetes, depression, social isolation, decline in function, falls, nursing home 
admission and onerous out-of-pocket expenses. ${ }^{6-10}$ In many cases incontinence can be improved, and even cured, when evidence-based diagnostic and treatment strategies are appropriately applied. ${ }^{6} 11-14$

It is a commonly held misconception that incontinence is a normal part of ageing. ${ }^{15}$ Not-for-profit organisations seek to raise continence awareness worldwide and promote treatment for incontinent individuals. Media campaigns, brochures and public awareness lectures attempt to destigmatise incontinence and increase help-seeking, but the effectiveness of these initiatives for reaching their target population remains unknown. ${ }^{15}$ Transmission of public health education via community organisations is an unexplored strategy for improving urinary symptoms. ${ }^{16}$ Data from randomised trials are needed to determine whether the delivery of an evidence-based continence intervention via community organisations is an effective method for treating incontinence.

The primary objective of this cluster randomised controlled trial was to compare the effectiveness of the three experimental continence promotion interventions against a control intervention on urinary symptom improvement in older women with untreated incontinence recruited from community organisations. A second objective was to determine whether changes in incontinence-related knowledge, attitudes and new uptake of risk-modifying behaviours explain improvements in incontinence. We hypothesised that continence education combined with evidence-based selfmanagement would yield the greatest improvement in incontinence symptoms, measured at the level of the individual, 3 months postintervention.

\section{METHODS}

Study design and oversight

A four arm, parallel-group, controlled, cluster randomised trial was conducted. The study design, recruitment methods and interventions have been reported. ${ }^{16}$ Clustering was at the level of the community organisation, from whence participants were recruited. The choice of a cluster design served to prevent contamination between participants in the same community organisation. The trial was designed by two of the authors and was overseen by the full investigator team, which had full access to the data. The data were collected at community organisations across the UK. All participants provided written informed consent.

\section{Study population and recruitment}

Inclusion criteria for community organisations included any organisation throughout the UK that consented to participate in the trial between November 2010 and September 2012. A community organisation was loosely defined as any not-for-profit group of individuals with a shared interest. These included interest and charity groups, seniors' housing groups, women's lobby groups and Asian caregiver associations. ${ }^{16}$ Organisations were contacted strategically by convenience sampling, word of mouth and referral. A research coordinator approached community organisations to join the trial by telephone, email and newspaper advertising.

The inclusion criteria for participants were women aged 60 years and older who reported urinary incontinence at least once weekly on the International Consultation on Incontinence Questionnaire (ICIQ), and who were not under active treatment for incontinence. For privacy reasons, many community organisations were uncomfortable screening their members for incontinence in advance, so eligibility to participate in the trial could only be ascertained by the research coordinator on the day of delivery of the intervention. ${ }^{16}$ Eligibility to participate in the trial was established by asking all attendees at the workshop to complete a baseline screening questionnaire on arrival. At this time, a study information sheet and a consent form were distributed to all participants. All women, regardless of eligibility or desire to enrol in the trial, were permitted to stay for the workshop. Only those women who wished to enrol in the trial submitted the signed consent form to the workshop facilitator following the delivery of the intervention, however all attendees were encouraged to submit the baseline screening questionnaire even if they were continent or did not wish to participate in the trial.

\section{Interventions}

The interventions were applied at the level of each cluster. The three experimental interventions to be tested were continence education, self-management including the distribution of an evidence-based risk factor reduction tool for incontinence, and a combined intervention that included both components. The sham control intervention was a lecture on health promotion for older women that addressed topics other than incontinence. All interventions were delivered once in group format to 8-16 women by the same facilitator at a venue of the organisation's choosing, and lasted 60-90 min. A slide presentation with a pre-established script prepared for the facilitator was delivered at each workshop.

The continence promotion intervention incorporated elements of constructivist learning that challenged older adults' erroneous beliefs about accepting incontinence as a normal part of ageing, and aimed to change attitudes and create new knowledge about the different types, aetiology, risk factors and treatment options for urine loss. ${ }^{16} 17$ The self-management workshop reviewed the self-management theory in an interactive format, and provided a customised evidence-based selfmanagement programme for risk factor modification for incontinence to each participant. ${ }^{18}{ }^{19}$ The programme targeted pelvic floor muscle weakness, obesity, consumption of caffeinated beverages, smoking, vision loss and constipation, with instructions on how to keep a bladder diary to help monitor symptoms. The content of the combined intervention condensed elements from the 
continence promotion workshop along with the selfmanagement theory, and provided the customised selfmanagement tool to participants. The control intervention addressed other non-bladder-related aspects of older women's health such as memory problems, polypharmacy, osteoporosis, nutrition, physical fitness and vision impairment.

\section{Study outcomes}

The primary outcome was the participant's global impression of improvement in incontinence symptoms, measured at 3 months postintervention by telephone interview using the patient's global impression of improvement (PGI-I) questionnaire. The PGI-I is a validated, single-item global rating of change scale that asks the patient to describe how their incontinence condition is now compared to how it was prior to the intervention (very much better, much better, a little bit better, no change, a little bit worse, much worse and very much worse).$^{20}$ The primary outcome, any improvement, was defined as a rating of a little bit better, much better or very much better. A secondary outcome, significant improvement, was defined as much better or very much better. The ICIQ, which measures the frequency, severity and bother from incontinence was used at baseline to screen participants for inclusion to the trial, and was repeated at follow-up. ${ }^{21}$ The ICIQ diagnostic item was used by participants to describe the type of incontinence at baseline. A pre-8-item and post-8-item questionnaire on knowledge and attitudes towards incontinence was administered at baseline and at 3-month follow-up, as were risk factors and behaviours related to incontinence. ${ }^{17}$ Risk factors and behaviours included performance of pelvic floor muscle exercises three times weekly (yes, no), daily consumption of one cup or more of tea or coffee (yes, no), fluid intake $>1.5 \mathrm{~L} /$ day (yes, no), weight and height (self-report) and smoking status (yes, no). At 3-month follow-up participants were asked whether they had sought treatment for urine leakage during the past 3 months. All follow-up interviews were performed by the research coordinator, who was blinded to participant identification.

The original study protocol sought to examine reductions in urinary frequency as measured on a bladder diary and reductions in the cost of pad use as primary and secondary outcomes respectively. However, as soon as recruitment for the trial started it became apparent that the distribution of bladder diaries and the objective measurement of pad use preintervention would not be possible. This occurred as a result of privacy concerns expressed by participating community organisations for revealing and sharing their members' names and contact information with the research team prior to the delivery of the workshops. ${ }^{16}$ The PGI-I was therefore used as the revised primary measure of effectiveness from the onset of the trial. Data on self-efficacy for managing incontinence were also collected, but are not reported in this article due to problems with comprehension of the visual analogue response scale during the 3-month telephone follow-up that occurred non-differentially among participants in all arms of the study.

\section{Randomisation and allocation concealment}

Group allocation occurred by non-stratified randomisation in blocked groups of four of consenting organisations that agreed to host a workshop. An independent statistician at a distant study site was responsible for randomisation using computer-generated random digits. Community organisations were informed that one of four workshops would be delivered on health topics of interest to older women, but not which one. In this way, group allocation was concealed from both the clusters and the individual participants, who were invited by the host organisation to attend a 'Women's Health Workshop'. The research coordinator remained unaware of group allocation at the time each community organisation was recruited to the trial because she was only informed which workshop to prepare for each organisation several days before each workshop. The trial is considered open-label because both the research facilitator who delivered the intervention and the participants who received it were aware of which intervention was being delivered.

\section{Sample size}

The trial was designed to detect a minimal $35 \%$ difference in the number of participants reporting any improvement (very much better, much better and a little bit better on the PGI-I) between the experimental and control conditions, assuming a rate of improvement in the control condition as high as $20 \%$, with $80 \%$ power and $\alpha 0.05$ two sided $(n=34)$. Using an inflation factor of 1.65 to account for an anticipated maximum intracluster correlation (ICC) of 0.05 and unequal cluster size yielded a recruitment target of 56 participants per group. ${ }^{22}$

\section{Statistical methods}

Differences in baseline characteristics between the four groups were determined. To assess the primary outcome we estimated the unadjusted risk difference (prevalence of the outcome) and 95\% CI via generalised estimating equations (GEEs) for participants who reported any improvement on the PGI-I. We repeated the same analysis for those who reported significant improvement. GEEs with an identity link and an exchangeable correlation structure were used to account for possible correlation between women in the same organisation. ${ }^{23}$ To adjust for the imbalance in potential confounders in the groups at baseline, additional analyses were conducted using multivariable logistic regression estimated via GEE with an exchangeable correlation structure. Potential confounders included age and baseline incontinence severity (ICIQ score) as continuous predictors, and living alone, depression, heart disease, falls, arthritis, 
diabetes, high blood pressure, educational status and general health perception as dichotomous predictors. Both intent-to-treat (ITT) and per protocol (PP) analyses were performed. For the ITT analysis, participants with missing data were assumed to have no change in incontinence status at 3-month follow-up. The number needed to treat was calculated as the inverse of the difference in absolute event rates between the experimental and control groups. ${ }^{24}$ We report intracluster (intracommunity organisation) correlation coefficients (ICC) from the marginal model using GEE with assumed exchangeable correlation structure and robust SEs. ${ }^{25}$ In cases where an ICC $<0$ was detected, we assumed a correlation structure of independence, but still used the robust variance estimator. The robust variance estimator is robust to misspecification of the correlation structure, so SEs, CIs and $\mathrm{p}$ values are still correct. To estimate adjusted mean group differences in ICIQ scores from baseline to 3-month follow-up, we used GEE with a Gaussian regression model for continuous outcomes and followed the same procedure outlined above.

Improvements in incontinence-related knowledge by intervention type for proportions of individuals responding correctly to each knowledge questionnaire item at baseline compared to 3-month follow-up were estimated using McNemar's test for matched pair analysis. Rates of improvement in self-reported risk modifying behaviours for incontinence were calculated, along with 95\% CIs. Differences in improvement rates between the intervention and the control groups were compared using
Fisher's exact test using a PP analysis. A difference in response for each health behaviour item that indicated adoption of a new risk modifying behaviour was defined as a positive change at a 3-month follow-up compared to baseline. Reduced coffee and tea intake refer to individuals who reduced their consumption to a single cup per day or less. Weight loss was determined by a positive response to the question, "Has your weight changed (yes, no) and if so, how much do you now weigh?" and evidence of self-reported current weight lower than selfreported weight at baseline. All statistical analyses were run using RStudio V.0.97.310.0, an integrated development environment for R.

\section{RESULTS}

\section{Study participants and follow-up}

Four hundred and twenty different community organisations were approached over an 18-month period to participate in the trial. Of these, $17 \%$ consented and succeeded in hosting an intervention, yielding 71 clusters that were randomised. Approximately one-quarter of the groups contacted refused; $2 \%$ expressed interest but were unable to organise a workshop; and a little over half failed to give any response although most of them had been followed up and had received extra information on the project. ${ }^{16}$ figure 1 depicts the study flow of the clusters and participants through the trial. Seven hundred and sixty-three women attended the workshops, of whom $322(42 \%)$ were known to be eligible for the trial. The mean number of participants recruited

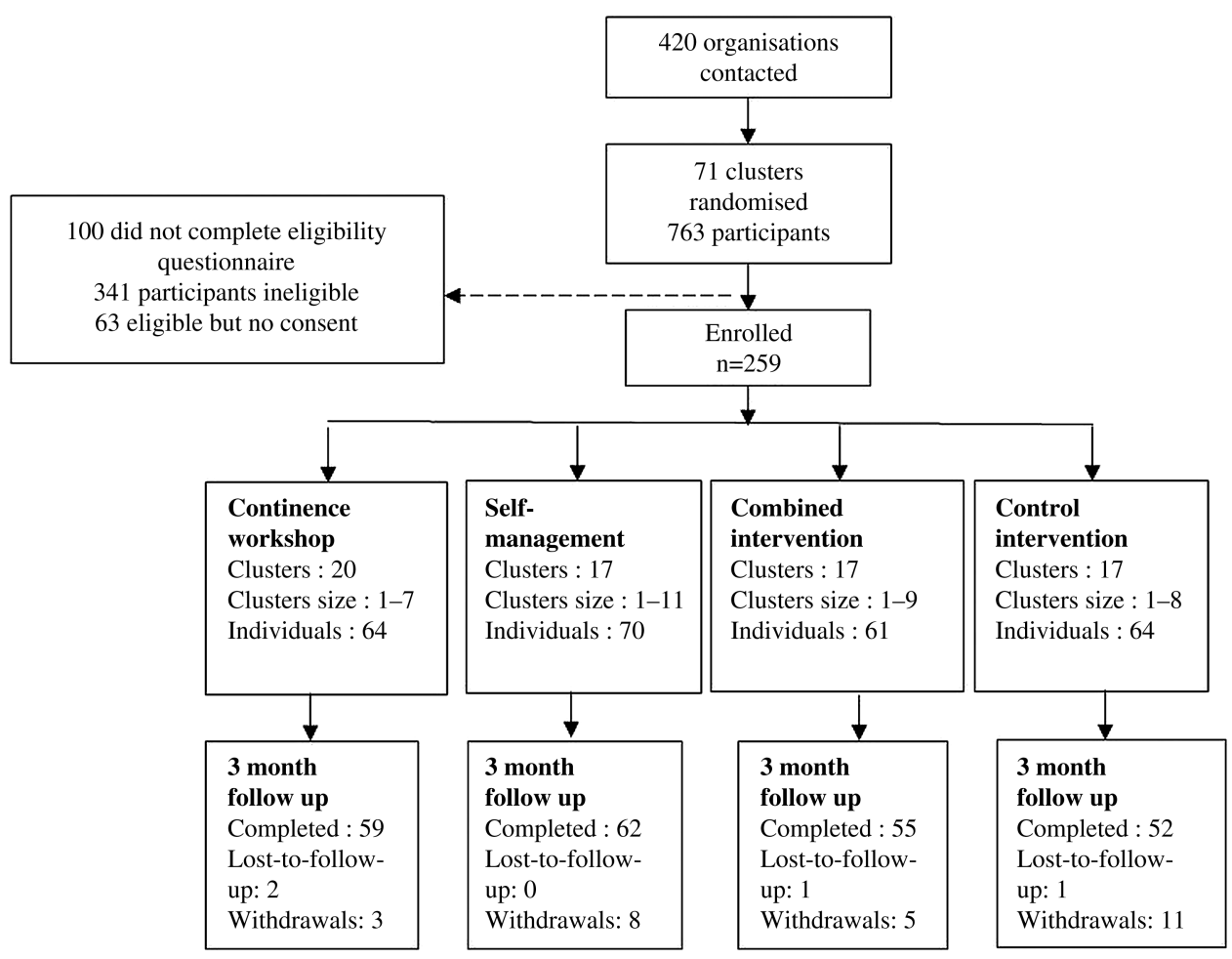

Figure 1 Flow of participants through the trial. 
from each cluster for the continence promotion group was $3+2$, whereas it was $4+2$ for the other three groups. Eighty per cent (259/322) of known eligible attendees to the workshops consented to take part in the trial. Two hundred and twenty-eight of these $(88 \%)$ were available for the 3-month follow-up. Table 1 compares the baseline characteristics of participants in each trial arm.

\section{Primary and secondary outcomes}

The highest rate of improvement in incontinence occurred in the combined intervention group, 66\% compared to $11 \%$ in the control group (prevalence difference $55 \%, 95 \%$ CI $43 \%$ to $67 \%$ ), yielding a number-needed-to-treat of 2. Thirty per cent of the combined group reported a significant improvement compared to $6 \%$ of controls (prevalence difference
23\%, $95 \%$ CI $10 \%$ to $36 \%$, number-needed-to-treat of 5). In the adjusted analyses, the likelihood of achieving a significant improvement in urinary symptoms from exposure to the combined intervention was five times greater than exposure to the control intervention (OR $4.94,95 \%$ CI 1.45 to 16.86 ). Compared to controls, the participants in the combined intervention reported an adjusted mean 2.05 point ( $95 \%$ CI 0.87 to 3.24 ) greater improvement on the ICIQ from baseline to 3-month follow-up. The adjusted mean difference in ICIQ scores was also significantly higher for the continence education group compared to the control group (1.33 point greater improvement (95\% CI 0.33 to 2.32)), but not for the self-management group. The PP analysis for the primary outcome and the ICC coefficients for each analysis are shown in table 2.

Table 1 Baseline characteristics and distribution of modifiable risk factors of participants

\begin{tabular}{|c|c|c|c|c|}
\hline & $\begin{array}{l}\text { Continence } \\
\text { education }(n=64)\end{array}$ & $\begin{array}{l}\text { Self-management } \\
(n=70)\end{array}$ & $\begin{array}{l}\text { Combined } \\
\text { intervention }(n=61)\end{array}$ & $\begin{array}{l}\text { Control } \\
\text { intervention } \\
(n=64)\end{array}$ \\
\hline & Mean \pm SD & & & \\
\hline Age & $70.8 \pm 7.9$ & $71.0 \pm 6.8$ & $70.4 \pm 6.7$ & $74.1 \pm 8.1$ \\
\hline \multirow[t]{2}{*}{ Mean ICIQ score $( \pm S D)^{*}$} & $8.5 \pm 4.4$ & $6.8 \pm 3$ & $7.3 \pm 5.6$ & $6.7 \pm 3.4$ \\
\hline & \multicolumn{4}{|c|}{$\%$ yes } \\
\hline Lives alone & $\overline{48.4}$ & 40.0 & 37.7 & 59.4 \\
\hline \multicolumn{5}{|l|}{ Education } \\
\hline $\begin{array}{l}\text { University degree or } \\
\text { equivalent }\end{array}$ & 31.2 & 45.7 & 37.7 & 19.0 \\
\hline \multicolumn{5}{|l|}{ General health perception } \\
\hline Good, very good, excellent & 53.1 & 85.7 & 80.3 & 75.0 \\
\hline Fair/poor & 45.3 & 14.3 & 16.4 & 25.0 \\
\hline Depression & 48.4 & 35.7 & 32.8 & 20.3 \\
\hline Heart disease & 35.9 & 25.7 & 16.4 & 21.0 \\
\hline Falls & 45.3 & 31.4 & 18.0 & 18.8 \\
\hline Arthritis & 78.1 & 52.9 & 44.3 & 57.8 \\
\hline Diabetes & 39.1 & 24.3 & 18.0 & 20.3 \\
\hline High blood pressure & 59.0 & 40.0 & 45.9 & 55.6 \\
\hline \multicolumn{5}{|l|}{ Type of incontinence } \\
\hline Stress only & 15.6 & 12.9 & 14.8 & 33.3 \\
\hline Urgency only & 32.8 & 35.7 & 29.5 & 20.6 \\
\hline Mixed & 45.3 & 42.9 & 55.7 & 39.7 \\
\hline \multicolumn{5}{|l|}{ Modifiable risk factors } \\
\hline $\begin{array}{l}\text { Performs pelvic floor muscle } \\
\text { exercises three times/week }\end{array}$ & 18.8 & 15.7 & 11.9 & 15.6 \\
\hline $\begin{array}{l}\text { Self-reported body mass } \\
\text { index }>27 \mathrm{~kg} / \mathrm{m}^{2} \dagger\end{array}$ & 53.2 & 53.0 & 42.4 & 49.2 \\
\hline $\begin{array}{l}\text { Drinks more than } 1.5 \mathrm{~L} \text { of } \\
\text { fluid/day }\end{array}$ & 43.8 & 44.3 & 54.1 & 37.5 \\
\hline $\begin{array}{l}\text { Drinks one cup of tea or } \\
\text { more/day }\end{array}$ & 85.9 & 84.3 & 73.8 & 84.4 \\
\hline $\begin{array}{l}\text { Drinks one cup of coffee or } \\
\text { more/day }\end{array}$ & 46.9 & 62.9 & 65.6 & 64.1 \\
\hline Smokes & 6.3 & 4.3 & 4.9 & 6.2 \\
\hline
\end{tabular}


Table 2 Prevalence, risk difference and ORs for self-reported improvements in incontinence at 3 months

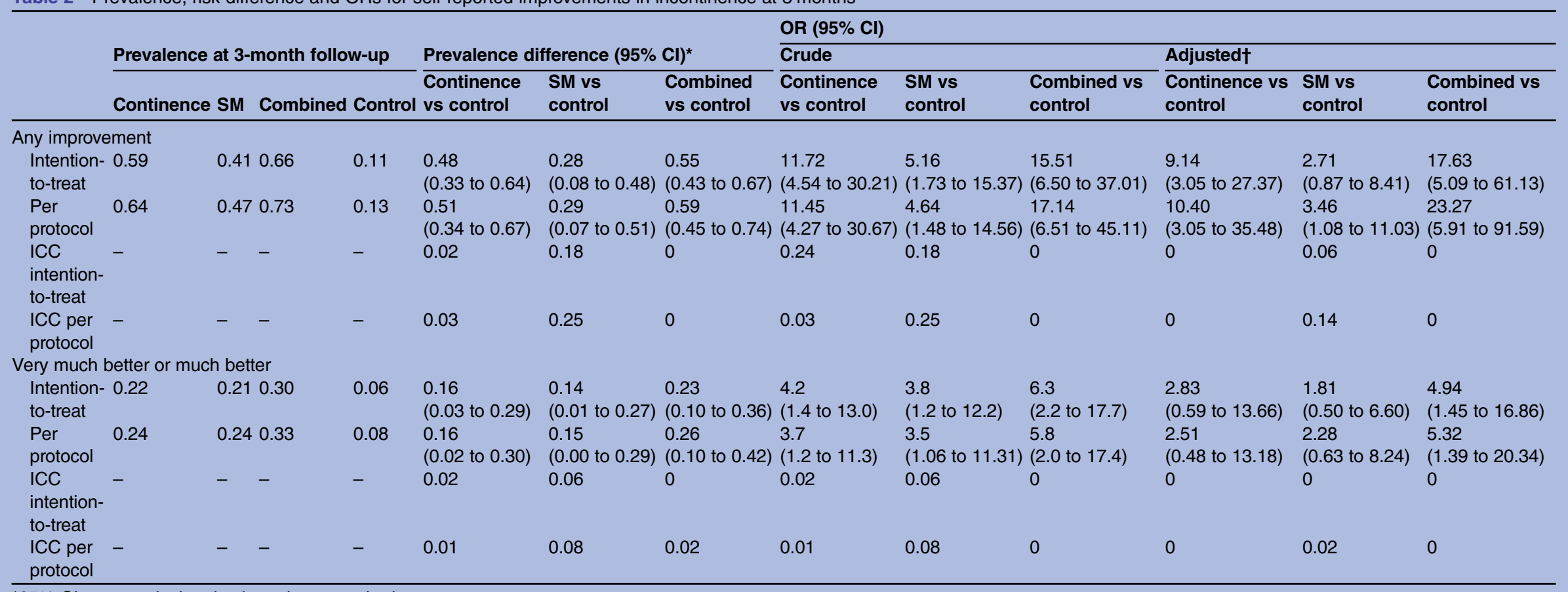

${ }^{*} 95 \%$ Cls were calculated using robust standard errors.

†Adjusted for age, living alone, depression, heart disease, falls, arthritis, diabetes, high blood pressure, educational status, general health perception and baseline incontinence severity score.

ICC, intracluster correlation; SM, self-management. 
Table 3 Change in incontinence-related knowledge

$\begin{array}{llll}\begin{array}{l}\text { Continence } \\ \text { education }(n=64)\end{array} & \text { Self-management }(n=70) & \begin{array}{l}\text { Combined } \\ \text { intervention }(n=61)\end{array} \quad \text { Control }(n=64)\end{array}$

1. Urinary incontinence is a normal part of ageing

$\begin{array}{lll}\text { Baseline \% agreement } & 73.0 & 79.7 \\ \text { 3-month follow-up \% agreement } & 36.2 & 63.9 \\ \text { p Value for change* }^{*} & <0.001 & \mathbf{0 . 0 2}\end{array}$

79.7

77.0

79.7

p Value for change* $\quad<0.001 \quad 0.02$

38.2

82.7

2. Once people start to leak urine, they are never able to control their urine again

$\begin{array}{lll}\text { Baseline \% agreement } & 41.9 & 32.9 \\ \text { 3-month follow-up \% agreement } & 29.3 & 17.7 \\ \text { p Value for change } & 0.12 & 0.06\end{array}$

$<0.001 \quad 0.73$

3-month follow-up \% agreement $29.3 \quad 17.7$

3. Urine leakage can be caused by many different things
Baseline \% agreement
88.9
3-month follow-up \% agreement $93.1 \quad 88.7$
$\mathrm{p}$ Value for change
$1 \quad 0.77$

92.8

36.1

50.8

$7.3 \quad 51.9$

$<0.001$

4. Wearing pads or diapers is the best way to manage urinary incontinence

$\begin{array}{lllll}\text { Baseline \% agreement } & 57.1 & 40.6 & 52.5 & 67.2 \\ \text { 3-month follow-up \% agreement } & 36.8 & 33.9 & 27.3 & 69.2 \\ \text { p Value for change } & \mathbf{0 . 0 3} & 0.11 & \mathbf{0 . 0 0 1} & 1 \\ \text { What you drink can contribute to urine leakage } & & & \end{array}$

What you drink can contribute to urine leakage

\begin{tabular}{lll} 
3-month follow-up \% agreement & 77.6 & 66.7 \\
\hline
\end{tabular}

$68.3 \quad 66.1$

$p$ Value for change $\quad 0.26 \quad 0.36$

$89.1 \quad 68.6$

$0.01 \quad 0.77$

6. How much you drink can contribute to urine leakage

$\begin{array}{lll}\text { Baseline \% agreement } & 72.6 & 65.2 \\ \text { 3-month follow-up \% agreement } & 77.6 & 71 \\ \text { p Value for change } & 0.63 & 0.65\end{array}$

p Value for change 0.63

$\begin{array}{lll}\text { Baseline \% agreement } & 61.3 & 74.3 \\ \text { 3-month follow-up \% agreement } & 77.6 & 77.4 \\ \text { p Value for change } & 0.08 & 0.69\end{array}$

$\begin{array}{lll}65.2 & 67.2 & 71.4\end{array}$

$\begin{array}{lll}71 & 76.4 & 65.4\end{array}$

$\begin{array}{lll}0.65 & 0.36 & 0.79\end{array}$

8. Exercising pelvic floor muscles can help control urine leakage

\begin{tabular}{lllll} 
Baseline \% agreement & 85.5 & 88.6 & 85.2 & 96.9 \\
3-month follow-up \% agreement & 96.5 & 96.7 & 98.2 & 98.1 \\
p Value for change & $\mathbf{0 . 0 4}$ & 0.13 & $\mathbf{0 . 0 2}$ & 1.0 \\
\hline
\end{tabular}

${ }^{*}$ McNemar's test for matched-pairs data.

Bold typeface indicate items that showed statistically significant change at $p<0.05$.

\section{Other outcomes}

Table 3 shows the changes in incontinence-related knowledge attributable to the receipt of each intervention. Participants exposed to the combined intervention showed the greatest acquisition in knowledge, exhibiting significant within-group improvement on six of eight questionnaire items. Participants learned that incontinence is not an inevitable or irreversible part of ageing, that losing weight, changing the type of fluid intake and performing pelvic floor muscle exercises can reduce urinary symptoms, and that wearing undergarment protection is not always the best way to manage incontinence.

The proportion of participants with modifiable risk factors for incontinence in each group at baseline is shown in table 1 . The adoption of various risk-modifying behaviours among participants occurred to a different degree as a result of exposure to all three experimental but not the control intervention (figure 2). At 3-month follow-up, the proportion of women reporting uptake of pelvic floor muscle exercises and weight loss was significantly higher in the continence education group ( $46 \%$ and $20 \%$, respectively), the self-management group $(34 \%$ and $20 \%)$ and the combined intervention group (53\% and 18\%) compared to controls $(8 \%$ and $3 \%$ ). Many women additionally reduced their coffee intake and total fluid intake. The proportion of women who made an appointment to consult a health professional for urine leakage was $19 \%$ in the continence promotion group, $7 \%$ in the self-management group, $16 \%$ in the combined intervention group and $4 \%$ in the control group.

\section{DISCUSSION}

In this cluster-randomised trial testing the effectiveness of three different continence promotion interventions, we found that health education combined with the delivery of an evidence-based self-management tool via community organisations to untreated older women yielded the highest rate of urinary symptom improvement in $66 \%$ of recipients, half of whom reported significant 


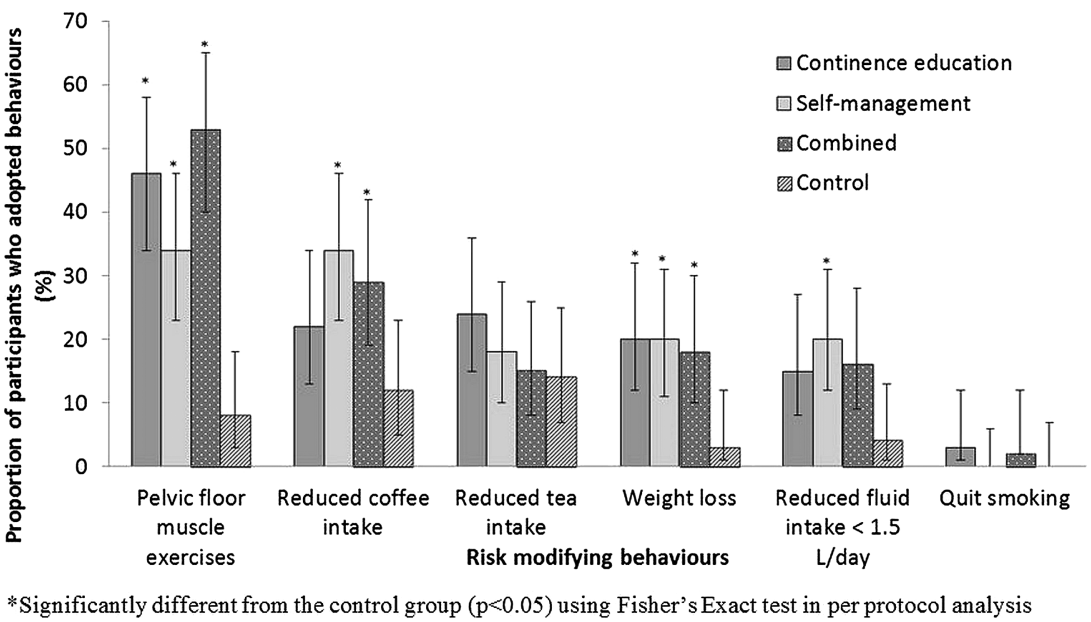

Error bars represent $95 \%$ confidence intervals

Figure 2 Change in risk-modifying behaviours at 3-month follow-up.

improvements in incontinence. These outcomes translate into a number-needed-to-treat of 2 and 5 , respectively, a magnitude of effect rarely achieved during public health interventions. Both new knowledge acquisition and the adoption of risk-modifying behaviours such as exercise and weight loss occurred as a result of community organisations' involvement in reaching untreated incontinent women outside the healthcare system.

\section{Strengths and weaknesses of the study}

This is the first randomised trial to test the effectiveness of continence promotion strategies through community outreach. Both explanatory mechanisms and final health outcomes were assessed, and the use of a cluster randomised design was chosen to avoid contamination of the control group. ${ }^{26} 27$ Our choice of comparator controlled for the placebo effect of participating in a group intervention. Breaches in the fidelity and quality of implementation of the intervention were minimised by having the same facilitator deliver each intervention. Improvements in urinary symptoms were shown with two validated measures, the PGI-I and the ICIQ. We believe the results have wide external validity as the community groups included women with varied educational levels and wide socioeconomic status.

The results of this study confirm findings from previous randomised trials suggesting a positive effect of continence education and self-monitoring strategies on urinary symptom improvement in untreated incontinent individuals. ${ }^{28-33}$ However all previous trials invited participants for clinical assessments prior to the delivery of the intervention, or involved individualised education sessions. The current trial delivered group continence interventions without medical or nursing evaluations, in a true public health approach, to both continent and incontinent women as part of the regular activities offered by each community organisation. Rates of improvement reported in this trial on the PGI-I were similar to or exceeded those reported in other studies using self-help booklets, in the range of $50 \%$. Owing to the nature of recruitment and delivery of the intervention via community organisations, bladder diaries and pad tests could not be collected preintervention. The results of our trial can therefore not be directly compared to other trials that used more objective measures of symptom improvement.

Other limitations also apply. Owing to the nature of recruiting potential participants, individuals could not be screened and enrolled in the trial prior to randomisation of the clusters. ${ }^{27}$ The result was an imbalance between groups, accounted for by analyses that took into account group differences in age, health status and baseline incontinence severity. The trial was not designed to measure the dose-response of knowledge acquisition and behaviour change on urinary symptom improvement. Thus only crude, dichotomous self-reported measures of behaviour change were collected and should be interpreted with caution.

\section{Relevance to the discipline}

The value of continence promotion interventions likely reflects the delivery method as well as the quality of the content. Group interventions that deliver continence education, self-management information or a combination of the two will improve incontinence symptoms in $59 \%, 41 \%$ and $66 \%$ of recipients, respectively. It is surprising that the self-management intervention alone was not associated with a significant improvement compared to sham control in this trial. This can potentially be explained by the fact that continence education was completely omitted from the self-management workshop, whereas some information on bladder functioning was provided to participants during the initial work that tested the self-management tool. ${ }^{19}$

\section{Implications for practice}

Implementation of community-based programmes that promote behavioural techniques as first-line management for incontinence support evidence for the superior efficacy and tolerability of conservative management 
approaches over a pharmacological treatment for incontinence. ${ }^{34}$ As 'silent sufferers' become better informed that effective strategies exist for improving urinary symptoms, patient demand for care will likely increase. Almost $20 \%$ of women made an appointment to discuss urine leakage with a health professional in the 3 months following receipt of the continence education intervention. Evidence-based guidelines exist for physicians to evaluate and manage urinary incontinence when firstline behavioural strategies fail, and will need to be more frequently applied..$^{511}$

In conclusion, continence education combined with self-management delivered via community organisations to untreated older women with incontinence leads to symptom improvement in one of every two recipients. At the current time, the majority of older women with incontinence do not seek care, and either self-manage their symptoms inappropriately or use protection to palliate urine leakage. ${ }^{1-4}$ As incontinence is associated with multimorbidity and other deleterious health effects, results from this trial provide strong justification for public health outreach via community organisations to reduce urine leakage among untreated individuals.

\author{
Author affiliations \\ ${ }^{1}$ Faculty of Medicine, Université de Montréal, Montréal, Quebec, Canada \\ ${ }^{2}$ Glasgow Caledonian University, Glasgow, UK \\ ${ }^{3}$ Departments of Medicine and of Epidemiology, Biostatistics \& Occupational \\ Health, McGill University, Montréal, Quebec, Canada \\ ${ }^{4}$ Department of Epidemiology, Biostatistics \& Occupational Health, McGill \\ University, Montréal, Quebec, Canada \\ ${ }^{5}$ Brunel Institute for Ageing Studies, Brunel University, Uxbridge, UK
}

Acknowledgements The authors would like to acknowledge the assistance of Mira Jabbour and Francine Giroux for their expert help with database management and the data analyses. Nikki Cotterill, Adele Long aided with recruitment in the Bristol area. The above-mentioned individuals received financial compensation for their contribution to this work. The authors express gratitude to all the participants who took part in this trial. Although not exhaustive, particular thanks are offered to the following organisations and groups for participating in the trial: the Women's Institute, AGE UK, the University of the Third Age, Queens Nursing Institute (Scotland), Kinship Carers, the Women's Guild, Hanover Housing Association, Good Neighbours, Asian Carers Groups and Older Peoples Forum throughout the UK.

Contributors CT designed the study and participated in the data analysis and interpretation, and wrote the first draft of the manuscript. RA was responsible for data collection, participated in the data analysis and interpretation and critically reviewed the manuscript. $A B$ was responsible for the data analysis and interpretation and critically reviewed the manuscript. DT conducted the analyses and reviewed the manuscript. EvdH helped design the study, participated in the study implementation, helped interpret the findings and critically reviewed the manuscript.

Funding This project was funded as part of the Canada-UK Aging Initiative in partnership with the Canadian Institutes of Health Research - Institute on Aging and the Economic and Social Research Council (UK). Agreement number 00912-001. Grant number 200909CUK-212417. CT is the recipient of a senior scientist research award from the Fonds de la recherche en santé du Québec.

Competing interests CT declares having been an advisory board member or received speaker honoraria from Pfizer, Watson, Astellas, Allergen and Ferring pharmaceuticals in the past 3 years, but not in relation to this work.
Provenance and peer review Not commissioned; externally peer reviewed.

Data sharing statement Patient-level data and the full dataset are available on request from the authors. Consent for data sharing was not obtained but the presented data are anonymised and the risk of identification is low.

Open Access This is an Open Access article distributed in accordance with the Creative Commons Attribution Non Commercial (CC BY-NC 3.0) license, which permits others to distribute, remix, adapt, build upon this work non-commercially, and license their derivative works on different terms, provided the original work is properly cited and the use is non-commercial. See: http://creativecommons.org/licenses/by-nc/3.0/

\section{REFERENCES}

1. Sexton CC, Coyne KS, Thompson C, et al. Prevalence and effect on health-related quality of life of overactive bladder in older Americans: results from the Epidemiology of Lower Urinary Tract Symptoms Study. J Am Geriatr Soc 2011;59:1465-70.

2. Tannenbaum C, Corcos J, Assalian P. The relationship between sexual activity and urinary incontinence in older women. J Am Geriatr Soc 2006;54:1220-4.

3. O'Donnell M, Lose G, Sykes D, et al. Help-seeking behaviour and associated factors among women with urinary incontinence in France, Germany, Spain and the United Kingdom. Eur Urol 2005;47:385-92.

4. Herschorn S, Gajewski J, Schulz J, et al. A population-based study of urinary symptoms and incontinence: the Canadian Urinary Bladder Survey. BJU Int 2008;101:52-8.

5. Bland DR, Dugan E, Cohen SJ, et al. The effects of implementation of the Agency for Health Care Policy and Research urinary incontinence guidelines in primary care. $J \mathrm{Am}$ Geriatr Soc 2003;51:979-84.

6. Subak LL, Wagner TH. Talking about incontinence: the first step toward prevention and treatment. JAMA 2010;303:2184-5.

7. Tannenbaum C, Gray M, Hoffstetter S, et al. Comorbidities associated with bladder dysfunction. Int J Clin Pract 2013;67:105-13.

8. Farage MA, Miller KW, Berardesca E, et al. Psychosocial and societal burden of incontinence in the aged population. Arch Gynecol Obstet 2008;277:285-90.

9. Holroyd-Leduc JM, Mehta KM, Covinsky KE. Urinary incontinence and its association with death, nursing home admission, and functional decline. J Am Geriatr Soc 2004;52:712-18.

10. Chiarelli PE, Mackenzie LA, Osmotherly PG. Urinary incontinence is associated with an increase in falls: a systematic review. Aust $J$ Physiother 2009;55:89-95.

11. Holroyd-Leduc JM, Tannenbaum C, Thorpe KE, et al. What type of urinary incontinence does this woman have? JAMA 2008;299:1446-56.

12. Goode PS, Burgio $\mathrm{KL}$, Richter $\mathrm{HE}$, et al. Incontinence in older women. JAMA 2010;303:2172-81.

13. Tannenbaum C, Bachand G, DuBeau CE, et al. Experience of an incontinence clinic for older women: no apparent age limit for potential physical and psychological benefits. $J$ Women Health Gend Based Med 2001;10:751-6.

14. Tannenbaum C, Brouillette J, Corcos J. Rating improvements in urinary incontinence: do patients and physicians agree? Age Ageing 2008;37:1-5.

15. Newman DK, Buckley B, Gordon D, et al. Continence promotion, education and primary prevention. In: Abrams P, Cardozo L, Khoury SWein A. eds. Incontinence. 5th International Consultation on Incontinence, February 2012. Paris: Health Publication Ltd, 2013:1789-1827.

16. Agnew R, van den Heuvel E, Tannenbaum C. Efficiency of using community organisations as catalysts for recruitment to continence promotion trials. Clin Trials 2013;10:151-9.

17. Tannenbaum C, Drali R, Holroyd-Leduc J, et al. Lessons learned: impact of a continence promotion activity for older community dwelling women. Neurourol Urodyn 2010;29:540-4.

18. Wilde $\mathrm{MH}$, Bliss DZ, Booth J, et al. Self-management of urinary and fecal incontinence. AJN 2014;114:38-45.

19. Holroyd-Leduc J, Strauss S, Thorpe K, et al. Translation of evidence into a self-management tool for use by women with urinary incontinence. Age Ageing 2011;40:227-33.

20. Yalcin I, Bump RC. Validation of two global impression questionnaires for incontinence. Am J Obstet Gynecol 2003;189:98-101.

21. Avery K, Donovan J, Peters TJ, et al. ICIQ: a brief and robust measure for evaluating the symptoms and impact of urinary incontinence. Neurourol Urodyn 2004;23:322-30. 
22. Eldridge SM, Ashby D, Kerry S. Sample size for cluster randomised trials: effect of coefficient of variation of cluster size and analysis method. Int J Epidemiol 2006;35:1292-300.

23. Ukoumunne OC, Forbes $\mathrm{AB}$, Carlin JB, et al. Comparison of the risk difference, risk ratio and odds ratio scales for quantifying the unadjusted intervention effect in cluster randomised trials. Stat Med 2008;27:5143-55.

24. McAlister FA, Straus SE, Guyatt GH, et al. Users' guides to the medical literature: XX. Integrating research evidence with the care of the individual patient. Evidence-Based Medicine Working Group. JAMA 2000;283:2829-36.

25. Hanley JA, Negassa A, Edwardes MD. GEE analysis of negatively correlated binary responses: a caution. Stat Med 2000;19:715-22.

26. Craig P, Dieppe P, Macintyre S, et al. Developing and evaluating complex interventions: the new Medical Research Council guidance. BMJ 2008;337:979-83.

27. Campbell MK, Piaggio G, Elbourne DR, et al. Consort 2010 statement: extension to cluster randomised trials. BMJ 2012;345:e5661.

28. Kincade JE, Dougherty MC, Carlson JR, et al. Randomised clinical trial of efficacy of self-monitoring techniques to treat urinary incontinence in women. Neurourol Urodyn 2007;26:507-11.

29. Wagg AR, Barron D, Kirby M, et al. A randomised partially controlled trial to assess the impact of self-help vs. structured help from a continence nurse specialist in women with undiagnosed urinary problems in primary care. Int J Clin Pract 2007:61: 1863-73.

30. Dougherty MC, Dwyer JW, Pendergast JF, et al. A randomised trial of behavioral management for continence with older rural women. Res Nurs Health 2002;25:3-13.

31. McFall SL, Yerkes AM, Cowan LD. Outcomes of a small group educational intervention for urinary incontinence: episodes of incontinence and other urinary symptoms. J Aging Health 2000;12:250-67.

32. Milne J. The impact of information on health behaviors of older adults with urinary incontinence. Clin Nurs Res 2000:9:161-76.

33. Goode PS, Burgio KL, Locher JL, et al. Effect of behavioral training with or without pelvic floor electrical stimulation on stress incontinence in women: a randomized controlled trial. JAMA 2003;290:345-52.

34. Shamliyan T, Wyman J, Kane RL. Nonsurgical treatments for urinary incontinence in adult women: diagnosis and comparative effectiveness. Comparative Effectiveness Review No. 36. (Prepared by the University of Minnesota Evidence-based Practice Center under Contract No. HHSA 290-2007-10064-I.) AHRQ Publication No. 11(12)-EHC074-EF. Rockville, MD. Agency for Healthcare Research and Quality. 2012. http://www.effectivehealthcare.ahrq. gov/reports/final.cfm 